\title{
Some considerations on perpendicular to grain stress in double-tapered glulam beams
}

\author{
Anna Al Sabouni-Zawadzka, Wojciech Gilewski ${ }^{*}$, and Jan Pełczyński \\ Warsaw University of Technology, Faculty of Civil Engineering, Warsaw, Poland
}

\begin{abstract}
The present paper focuses on the analysis of tensile stresses perpendicular to the grain in simply supported double-tapered beams made of glued laminated timber. Two approaches are compared: a code design verification method and a finite element method (FEM) in terms of the linear theory of elasticity with plane stress assumption. The values and distributions of the analysed stresses are determined, depending on the apex height and orthotropic properties of wood.
\end{abstract}

\section{Introduction}

Simply supported beams are one of the most commonly used structural members in timber engineering. They can be tapered or have constant cross-section. Tapered beams are often used as roof elements, as their geometry naturally provides a desired roof inclination. Furthermore, the material of such beams is used with better efficiency, because the geometry tends to reflect the bending stress distribution under most load cases. In the present paper double-tapered glulam beams are considered, with a standard geometry described in Eurocode 5 [1] (Fig. 1). In the design and analysis of such beams, apart from shear and bending stresses, tensile stress perpendicular to the wood fibres should be taken into account and reinforcement against this stress should be considered if needed [2-4].

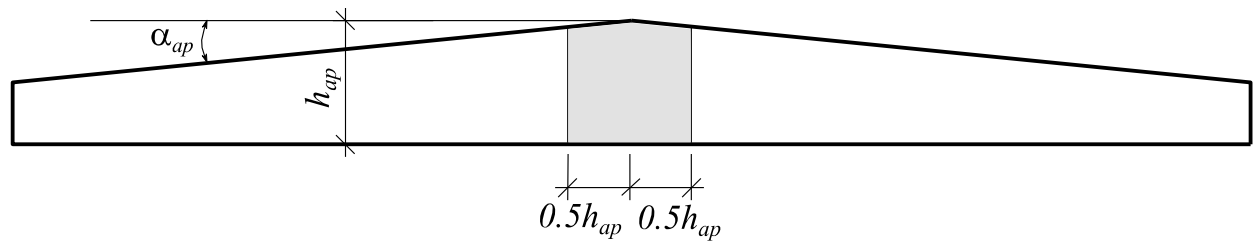

Fig. 1. Double-tapered beam considered in Eurocode 5 with the apex zone.

According to the design standard [1] normal stress perpendicular to grain should be evaluated in the apex zone, which is marked in Figure 1. The width of this zone is equal to the apex height. Eurocode 5 provides two alternative formulae for calculation of the stress perpendicular to grain, depending on the load type:

* Corresponding author: w.gilewski@il.pw.edu.pl 


$$
\begin{gathered}
\sigma_{t, 90, d}=k_{p} \frac{6 M_{a p, d}}{b h_{a p}^{2}}, \\
\sigma_{t, 90, d}=k_{p} \frac{6 M_{a p, d}}{b h_{a p}^{2}}-0,6 \frac{p_{d}}{b},
\end{gathered}
$$

where: $M_{a p, d}$ is the design moment at the apex, $b$ is the width of the beam, $h_{a p}$ is the height of the beam at the apex, $p_{d}$ is the uniformly distributed load acting on the top of the beam over the apex area and $k_{p}=0.2 \tan \left(\alpha_{a p}\right)$. Whereas the first expression (1) is accepted and recommended (unless the National annex states otherwise) for all load cases, the second one (2) may be used only when the beam is loaded with a uniform load applied to the top of the apex zone.

According to Eurocode 5, the biggest tensile stress perpendicular to the grain should satisfy the expression

$$
\sigma_{t, 90, d} \leq k_{d i s} k_{v o l} f_{t, 90, d},
$$

where: $f_{t, 90, d}$ is the design tensile strength perpendicular to grain, $k_{d i s}$ is a factor which takes into account the effect of the stress distribution in the apex zone and for double-tapered beams equals $1.4, k_{v o l}$ is a volume factor given by the formula

$$
k_{\text {vol }}=\left(\frac{V_{0}}{V}\right)^{0,2}
$$

where: $V_{0}$ is the reference volume of $0.01 \mathrm{~m}^{3}, V$ is the volume of the apex zone (see Fig. 1) and should not be taken greater than $2 V_{b} / 3$, where $V_{b}$ is the total volume of the beam.

In this paper a simply supported double-tapered glulam beam with varying apex height is considered. Geometry of the beam, support scheme and analysed load cases are presented in Figure 2.

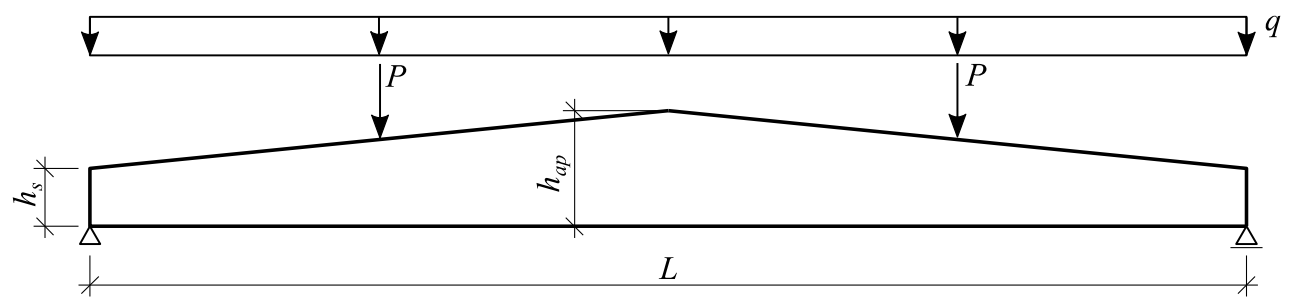

Fig. 2. Double-tapered beam with geometry, support scheme and loads.

The purpose of this study is to determine the level and distribution of normal stresses perpendicular to the grain in the analysed example of a glulam beam depending on the apex height and to compare two approaches to the structural analysis of such a system: the design code verification [1] and the finite element method (FEM) [5].

\section{Analysis}

\subsection{Design code verification}

The analysed beam (Fig. 2) is made of glued laminated timber GL28h. Material properties were taken from the currently valid design standard EN 14080 [6] and compared to the ones from the withdrawn standard EN 1194 [7]: characteristic density $\rho_{k}=425 \mathrm{~kg} / \mathrm{m}^{3}$ [6] and $\rho_{k}^{\prime}=410 \mathrm{~kg} / \mathrm{m}^{3} \quad$ [7], characteristic tensile strength perpendicular to grain 
$f_{t, 90, k}=0.5 M P a[6]$ and $f_{t, 90, k}^{\prime}=0.45 M P a$ [7]. The design values of strength $f_{t, 90, d}$ were calculated using the following expression from Eurocode 5:

$$
f_{t, 90, d}=k_{\bmod } \frac{f_{t, 90, k}}{\gamma_{M}},
$$

where: $k_{\text {mod }}$ is a modification factor taking into account the effect of load duration and moisture content and was taken as 0.8 (for service class 2 and medium-term action), $\gamma_{M}$ is the partial factor for material properties and for glulam equals 1.25. The design tensile strengths obtained from the above expression are: $f_{t, 90, d}=0.32 \mathrm{MPa}[6]$ and $f_{t, 90, d}^{\prime}=0.29 \mathrm{MPa}[7]$.

In the analysis the following geometry was adopted: $L=20 \mathrm{~m}, h_{s}=1.0 \mathrm{~m}$, $h_{a p}=\{1.25 ; 1.5 ; 1.75 ; 2.00 ; 2.25 ; 2.50 ; 2.75\} m$ (see. Fig. 2 ) and width $b=0.2 m$. Two load cases were considered: a uniformly distributed load $q=25 \mathrm{kN} / \mathrm{m}$ acting on the top of the beam and two concentrated forces $P=25 \mathrm{kN}$ applied in $1 / 4$ and $3 / 4$ of the beam span $L$. The loads were chosen in such a way so that the maximum bending moment had the same value of $1250 \mathrm{kNm}$ in both load cases. Moreover, deadweight of the beam was considered in some of the performed analyses.

Figure 3 shows how the apex height of the beam influences the maximum value of tensile stress perpendicular to the grain. The calculations were performed twice: in case when concentrated forces expression (1) was used and for the distributed load formula (2) was applied.

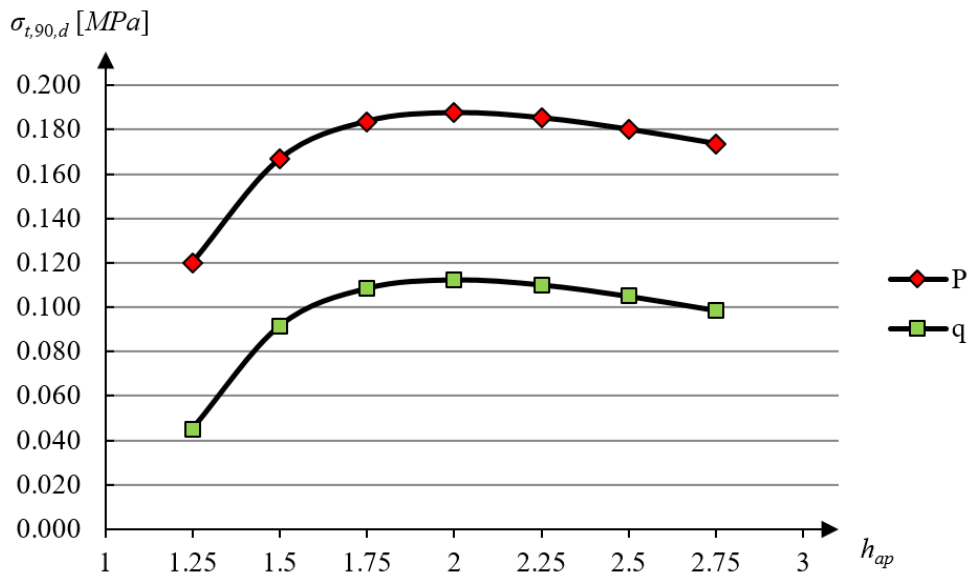

Fig. 3. Maximum tensile stress perpendicular to grain for two load cases.

It should be noticed that application of the expression (2) results in obtaining considerably lower values of stresses than in the case of the recommended formula (1). In both cases an extremum can be observed for the apex height of about 2,0 $\mathrm{m}$.

In order to check the condition (3) a ratio $\sigma_{t, 90, d} / k_{d i s} k_{v o l}$ was considered (Fig. 4). In the analysed example the condition (3) is fulfilled for all the considered apex heights only in case of the distributed load and application of the expression (2). In case of concentrated forces the condition (3) is satisfied only for lower apex heights - in taller beams additional reinforcement against delamination would have to be applied. Moreover, it can be observed that the maximum value of the beam height for which the reinforcement is needed depends on the design standard that is applied. The new standard [6] gives greater values of strengths perpendicular to grain and thereby allows to design taller beams without reinforcement. 
Analysis of the diagram in Figure 4 imposes a question, why the stresses calculated using the expression (2) are so much lower than the ones obtained from the formula (1). For example, the beam with $h_{a p}=2.25 \mathrm{~m}$ and a distributed load applied on the top does not have to be reinforced if the expression (2) is used but if the formula (1) is applied (which is recommended by Eurocode 5 for all load cases) the reinforcement is required. Such a discrepancy may result from the particular character of a uniformly distributed load acting on the top of the beam in the apex zone, which presses down the upper layers of glulam causing a reduction of tensile stresses.

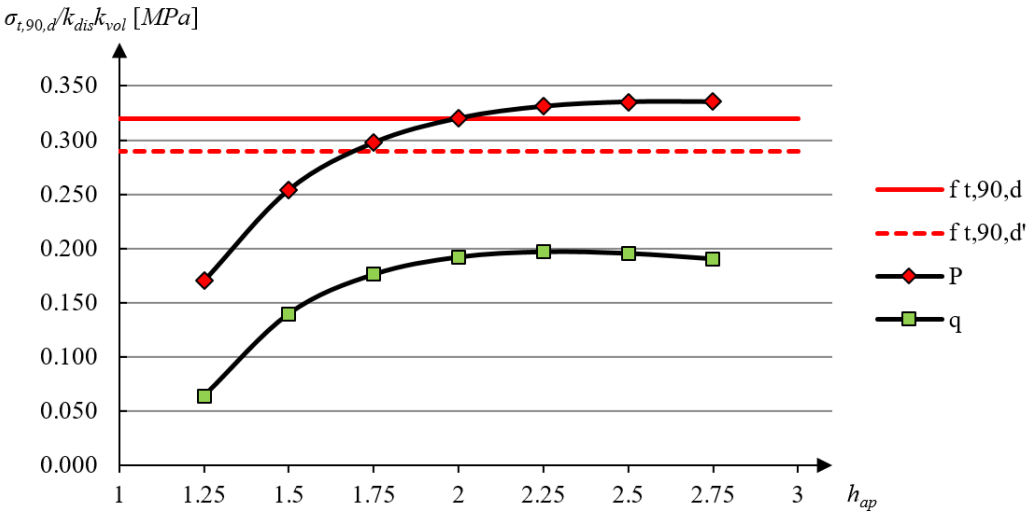

Fig. 4. Maximum tensile stress perpendicular to grain for two load cases, including factors $k_{\text {dis }}$ and $k_{v o l}$.

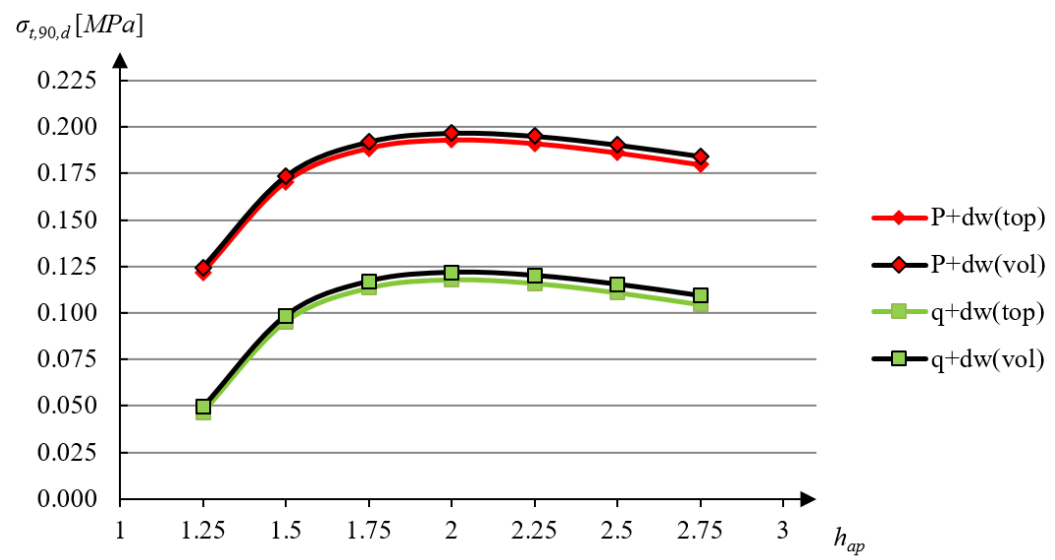

Fig. 5. Maximum tensile stress perpendicular to grain for two load cases, including deadweight.

In Figure 5 results of the analysis that included deadweight are presented. Two load cases were considered: concentrated forces with deadweight and distributed load with deadweight. For each case the calculations were performed twice - deadweight was applied either to the whole volume or to the top.

In the analysed example the deadweight of the structure is $3,6 \%$ of the total load so its influence on the considered stresses is rather little. Moreover, it practically does not matter if it is applied as volume forces or to the upper surface of the beam - such a hypothetical application of deadweight on the beam top causes insignificant reduction of stresses perpendicular to the grain, so it might be used if needed for simplification of the analysis. 
Figure 6 shows how the volume factor $k_{v o l}$ depends on the apex height. It might be observed that the value of this factor decreases with an increase of the apex heights, so the taller the beam is, the more rigorous the condition (3) becomes.

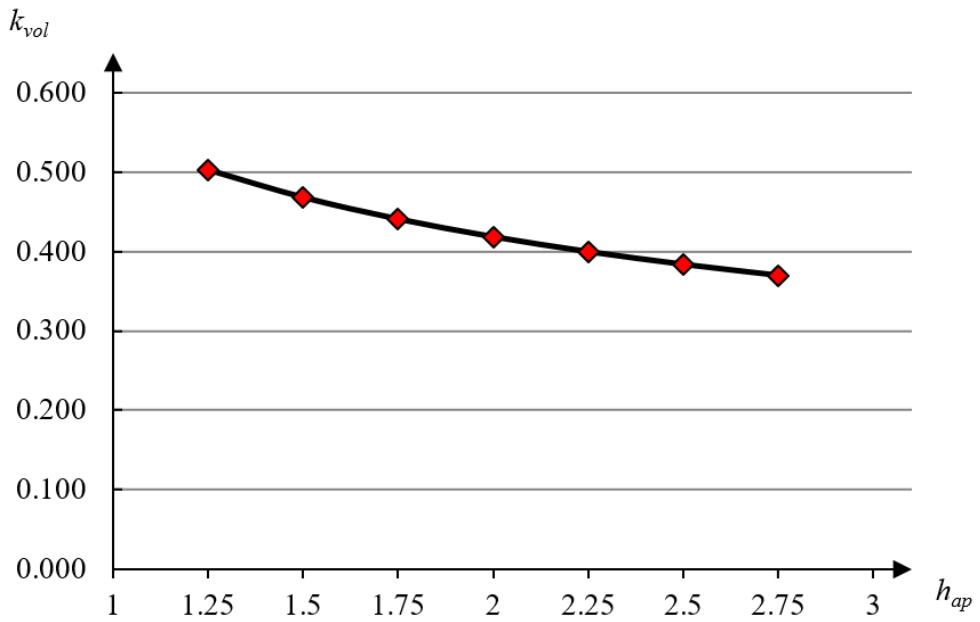

Fig. 6. Volume factor.

\subsection{Finite element analysis}

In order to compare two approaches to the analysis of a double-tapered glulam beam, the structure described in the previous section (Fig. 2) was modeled using a 2D linear theory of elasticity in plane stress condition. Four cases of material properties were considered (Tab. 1): two types of orthotropy with the parameters taken from the withdrawn [7] and valid [6] design standard for timber class GL28h, a non-standardized orthotropy and an isotropy as a borderline case. The same geometry, support scheme and loads were applied as in the case of the design code verification. The calculations were performed using the Abaqus FEM software [8]. Two dimensional 8-node biquadratic solid plane stress elements (CPS8R) with reduced integration and seed size of $0.1 \mathrm{~m}$ were used [8].

Table 1. Material parameters

\begin{tabular}{|c|c|c|c|c|}
\hline Material & $E_{1}[\mathrm{MPa}]$ & $E_{2}[\mathrm{MPa}]$ & $v_{12}$ & $G_{12}[\mathrm{MPa}]$ \\
\hline Ort-1 (EN 14080) & 12600 & 300 & 0,35 & 650 \\
\hline Ort-1' (EN 1194) & 12600 & 420 & 0,35 & 780 \\
\hline Ort-2 & 12600 & 2450 & 0,35 & 1428 \\
\hline Iso (Isotropy) & 12600 & 12600 & 0,35 & 4667 \\
\hline
\end{tabular}

The FE analysis was performed in order to determine maximum values and distributions of tensile stresses perpendicular to grain and to compare these results with the ones obtained from the calculations according to the design standard. 

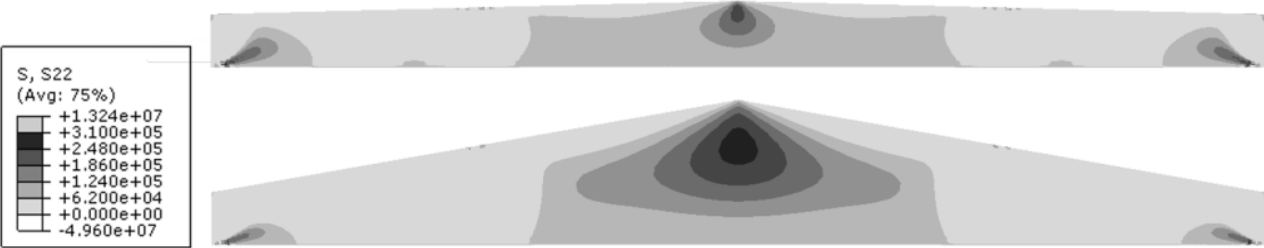

Fig. 7. Distribution of positive stress perpendicular to the grain under concentrated forces for the lowest and highest apex.
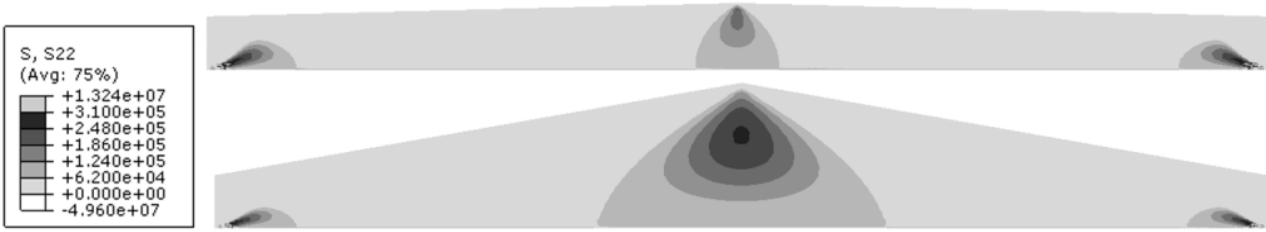

Fig. 8. Distribution of positive stress perpendicular to the grain under distributed load for the lowest and highest apex.

Figures $7 \div 8$ present examples of distributions of positive tensile stresses perpendicular to the fibres for the lowest and highest apex considered in the analysis and for two load cases: concentrated forces and distributed load.

The area of positive tensile stress in case of the beam loaded with two concentrated forces (Fig. 7) is much wider than the apex area considered in Eurocode 5 (Fig. 1). This is particularly noticeable for low apex height. However, taking into account the level of stresses, the area of the zone in taller beam is wider. The zone of positive tensile stresses under uniformly distributed load is considerably smaller than in the case of concentrated forces. For distributed load the width of the zone in both taller and lower beams is close to the double apex height, which is also more than the width suggested in the design standard.

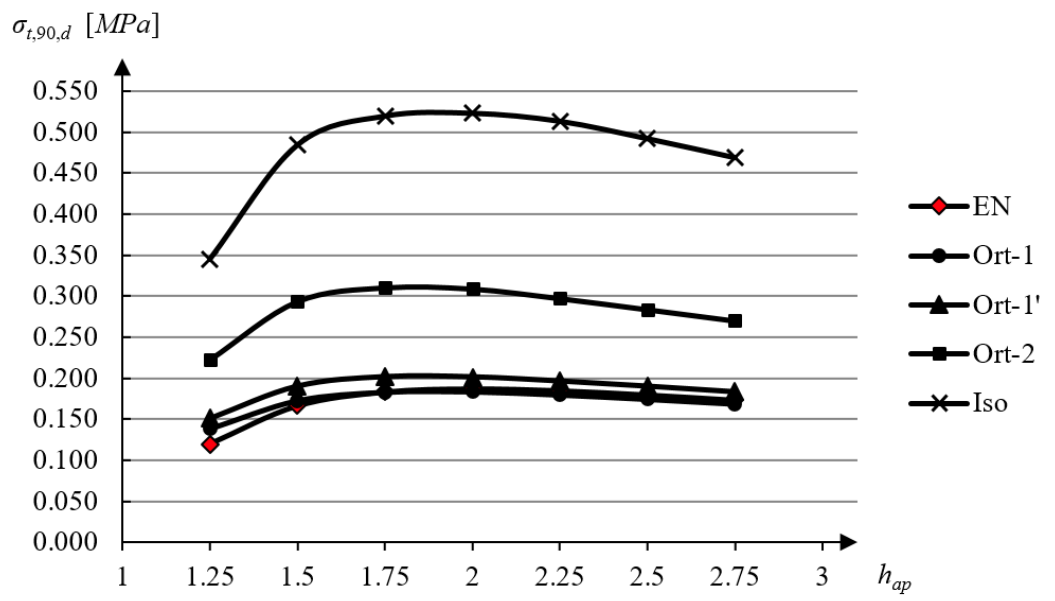

Fig. 9. Influence of material properties on tensile stress perpendicular to the grain - concentrated forces.

The maximum values of normal stresses perpendicular to the grain depend on the apex height and adopted material properties (see Fig. 9 $\div 10$ ). Higher stress values are obtained for materials close to isotropy. Assumption of strong orthotropic properties of the material 
leads to smaller stress variation with regard to the apex height. It is worth mentioning that the greatest value for isotropy occurs when the apex height is two times bigger than the height of the beam in the support zone - the extremum moves in the direction of $h_{a p}=1,75 \mathrm{~m}$ for beams with different orthotropic properties, regardless of the type of load (see also [9]).

It should be noticed that the maximum values of stresses from the design code

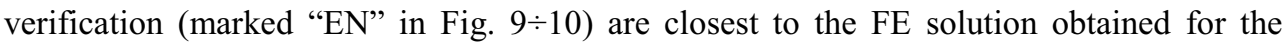
material parameters taken from the valid design standard [6].

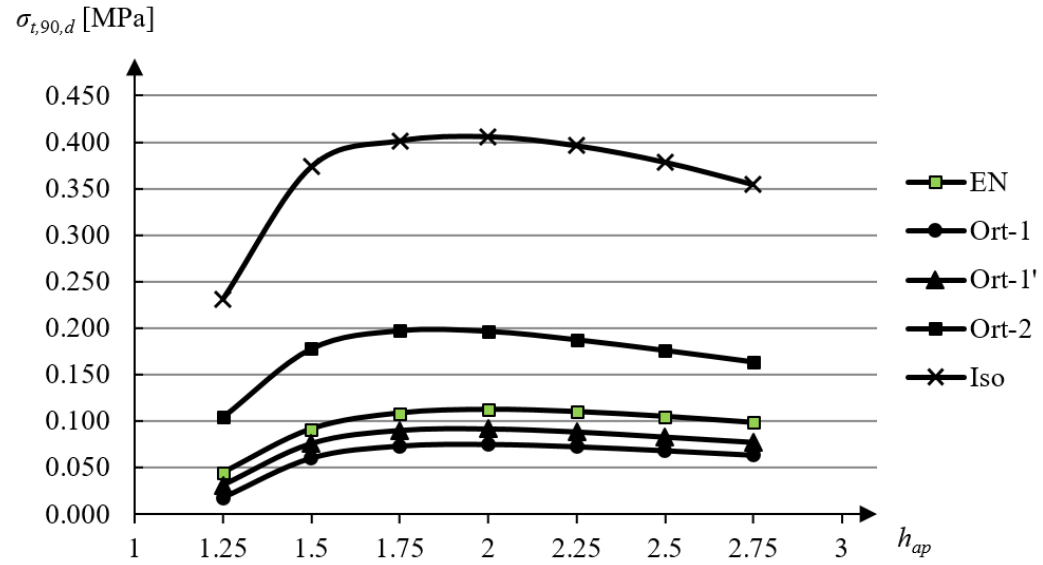

Fig. 10. Influence of material properties on tensile stress perpendicular to the grain - distributed load.

Diagrams presented in Figures $11 \div 12$ show how the adopted material properties influence the volume of the zone of positive tensile stresses perpendicular to the grain. Curves marked with "EN" correspond to the apex volume $V$ calculated according to Eurocode 5. It can be noticed that the values obtained from the FE analysis are closer to the ones calculated using the design standard in the case of distributed load. When concentrated forces are applied the differences between two considered approaches are more significant.

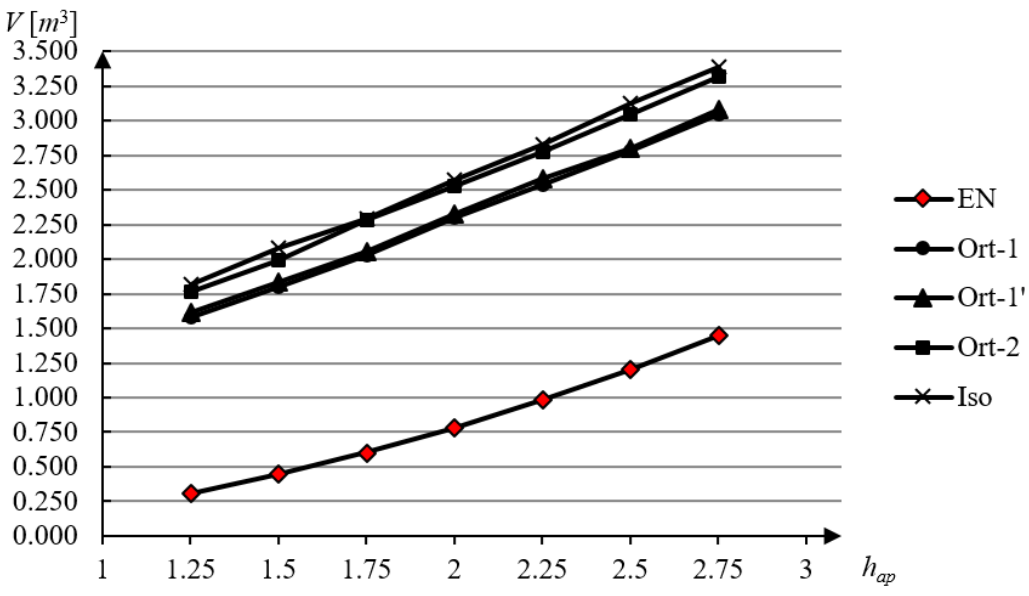

Fig. 11. Volume of the zone of positive stresses perpendicular to the grain - concentrated forces. 


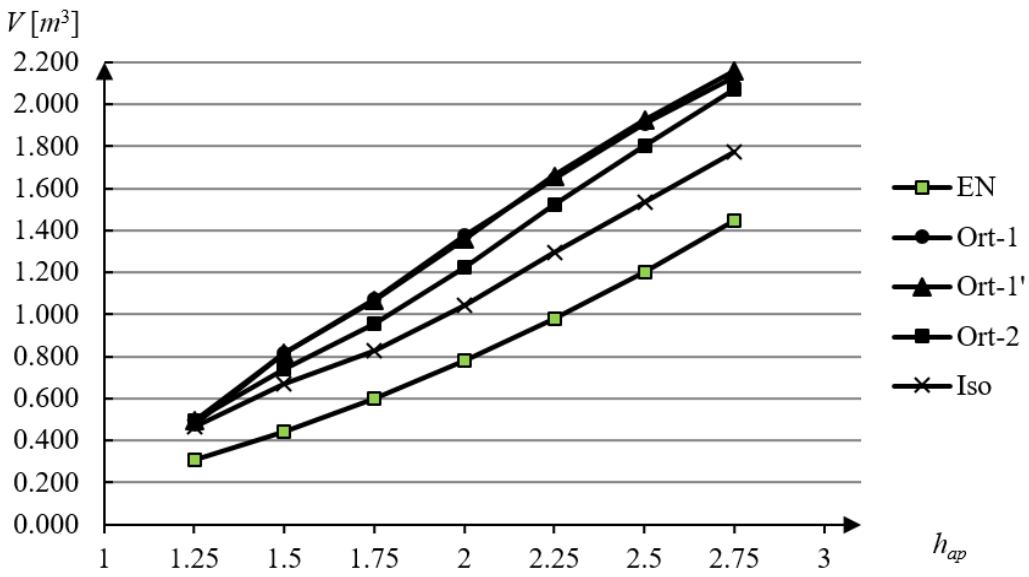

Fig. 12. Volume of the zone of positive stresses perpendicular to the grain - distributed load.

\section{Concluding remarks}

The design and structural analysis of double-tapered beams, made of glued laminated timber, require taking into account tensile stress perpendicular to the wood fibres. According to the design standard [1] such stresses should be evaluated in the apex zone, which has a width equal to the apex height. Examples presented in this paper indicate some important differences between two approaches to the structural analysis of such beams: analysis according to the design standard [1] and the finite element method (FEM) [5]. The levels and distributions of tensile stresses perpendicular to the grain are determined depending on the apex height and material properties and differences between Eurocode 5 and FEM are highlighted.

\section{References}

1. EN 1995-1-1:2004 (2004)

2. S. Franke, B. Franke, A.M. Harte, Constr. and Build. Mater. 97, 2 (2015)

3. S. Thelandersson, H.J. Larsen Timber Engineering (John Wiley \& Sons, Chichester, England, 2003)

4. S. Vratusa, M. Kitek, V. Kilar, Drewno 54, 185 (2011)

5. O.C. Zienkiewicz, R.L. Taylor, The finite element method. Vol. 1. The basis (Butterworth-Heinemann, New Jersey, 2000)

6. EN 14080:2013 (2013)

7. EN 11994:1999 (1999)

8. ABAQUS Documentation 2017

9. H. Danielsson, Design and perpendicular to grain tensile stress in double-tapered glulam beams, [publisher information missing] (2010) 